\title{
Product Platform: Trends and Opportunities
}

\author{
Evandro CERQUEIRA ${ }^{1}$, Rafael VOLTOLINI and Milton BORSATO \\ ${ }^{a}$ Federal University of Technology - Paraná (UTFPR), Brazil
}

\begin{abstract}
Increasing market competitiveness forced industries to seek ways to reduce production costs and increase profitability. Companies operating in different markets face different customer expectations. Thus, it is necessary to develop products that meet the most varied market requirements, without demanding the high investment costs that product customization demands. The development of product platforms has helped companies to lower the cost of mass customization. The main benefit of using platforms is the reduction of investment in customized product development. A platform allows creating specific product families for each market application. In view of this context, a bibliographical review was performed with the objective of finding the state of art for the theme and mapping the research opportunities. For this activity, the research tool ProKnow-C (Knowledge Development Process - Constructivist) was considered. From a quantitative analysis, the most relevant papers were identified, based on authors, periodicals, the relevance of articles and keywords. Then, the systemic analysis of articles related to the theme evidences the frontiers of knowledge. The main objectives, methodologies, and opportunities for future research were mapped from 33 articles selected from the database. In the end, 3 gaps were identified for future work.
\end{abstract}

Keywords. Product Development, Product Platform and Mass Customization

\section{Introduction}

Many manufacturers that work in the development of products are facing a big challenge operating in different markets that require customized products. Faced with this new reality, companies are forced to make strategic decisions, which can generate high development and production costs. For example, the development of specific products to meet the demands of each market, which is accompanied by high investments. These investments tend to grow with the increasing of markets served by the company. Economically it is not feasible since the costs of development and production of different products demand high costs for the company [1].

In this way, companies have three alternatives: i) they do not serve all markets, ii) reduce the range of products, or iii) develop families from product platforms. The first alternative can lower profits and give opportunities for competitors. The second, to reduce the product range is to offer the same products for different applications. The risks of this alternative are the fact that the product does not meet customers expectations. The third alternative, considered the most appropriate, offers different products to different markets at a lower cost. It allows the flexibility of creating different products, and their variants, at the lowest investment cost, since the basis for developing new product options is common [2]. With the increasing investment in

\footnotetext{
${ }^{1}$ Corresponding Author, Email: evandrocerqueira@yahoo.com.br.
} 
product platforms for different markets, the concept of mass customization is created, which was only possible due to the development of product platforms [3].

The present work has the objective to find the state of art of product platforms development, as well to find research opportunities in this area. In order to carry out the research activity, ProKnow-C tool (Knowledge Development Process - Constructivist) [4] was used. This tool allows a systematic review of the literature, to develop scientifically based research [5].

This article is structured as follows: section 1 describes the methodological aspects of the work, the detailed development of the research is presented in section 2, section 3 presents the conclusion of this study and section 4 ends with the bibliographical references that were used throughout the document.

\section{Methodology}

This chapter describes the methodological procedures used in the research. According to [6], research can be classified according to its nature, approach to the problem, its objectives and also the technical procedures. In this way, this research can be classified as exploratory, for developing knowledge in the researcher about the subject and descriptive for describing some characteristics found in the articles. Regarding the approach, it is considered qualitative and quantitative, by measuring the phenomena in numbers. Regarding nature, the research is considered applied, due to the possibility of applying the knowledge generated in this work [7]. Regarding the technical procedures, it is bibliographical, since it uses material already published to develop knowledge in relation to the subject.

For the construction of the bibliographic portfolio, the process for mapping knowledge ProKnow-C was used. This method was developed with the purpose of facilitating the construction of the bibliographic portfolio since the high volume of articles found requires a well-elaborated material selection process. This process can be divided into stages consisting: i) selection of bibliographic portfolio (PB), ii) bibliometric analysis, iii) systemic analysis, and iv) definition of the research question, general and specific objectives [8].

\section{Research development}

\subsection{Bibliographic portfolio selection}

Once the research scope was defined according to the study topic, some restrictions were established in order to select the bibliographic portfolio. The first restriction concerns the publication dates of the articles, where the range is between 2014 to 2018 . The objective is to search for more recent articles, which leads to finding the latest trends and opportunities on the study topic. The second restriction is related to the language of the publication, which was conditioned only to English. Since most publications, including the most relevant ones, are in English, no loss of important work is expected. The last restriction was the selection of only research articles.

For the selection of the database, research axes were defined related to the theme proposed by the work. According to the research objectives, 3 axes were defined: (i) Product Development, (ii) Platform, and (iii) Features. For each axis, keywords were 
created with the aim of covering as many relevant articles as possible, within the main theme product platform development (Table 1).

Table 1. Axles and keywords.

\begin{tabular}{ll}
\hline Axle name & Keywords \\
\hline Product development & New Product Development, Product Development Process, NPD, PDP, \\
& Product Design \\
\hline Platform & Mass Customization, Product Family Design, Commonality, \\
& Customization, Product Family, Modularity, Product Line, Product \\
& Variety, Modular-Structure Product, Scalability, Market-Based Product \\
& Design, Platform Leveraging \\
\hline Features & Cost, Quality, Customer Satisfaction, Function, Cost Improvement, Cost \\
& Saving \\
\hline
\end{tabular}

Table 1 presents the research axes and respective keywords used to form the article database. With the research axes defined, it is necessary to form the word string to be inserted in each database. In order to perform the search, it is needed to use logical operators. The operators used are: AND, OR, and NOT. The logical operators, combined with the keywords in each search axis, form the set of word string to be inserted in the search fields of databases.

With the word string defined, the search databases for the article portfolio were selected. The databases were chosen according to their academic relevance. The chosen databases are Scopus, Web of Science, Proquest, Engineering Village, Science Direct, Emerald. The next step was to perform de search on the databases. This activity was carried out in the period from 07/07/2018 to 05/07/2018.

As a result, 1370 articles were found in the databases.

\subsection{Articles database filtering process}

With the established bibliographic portfolio, Mendeley Desktop reference manager was used. This tool has several functions that facilitate the process of filtering the articles. The filtering process starts with the search for duplicate articles, a feature available in the software permit to do it automatically. Thus, 49 duplicated articles were found, remaining 1218 non-duplicate articles. The next step is to read the titles, with the aim of eliminating articles that are not related to the theme. After reading, 947 articles were eliminated, remaining 271 non-duplicated articles in line with the theme.

The next step was to verify the scientific recognition of each article. The articles were imported into Microsoft Excel, where it was possible to sort the articles according to the criteria established in Proknow-C. Google Scholar was used to finding the number of citations of each article [9]. In this step, 9 articles were not found, leaving 262 articles to be sorted in decreasing order by the number of citations. The next step corresponds to the application of the Pareto principle [10]. The sum of the number of citations of the 262 articles was carried out, with a total of 1720 citations. According to the Pareto principle, $80 \%$ of the total citations correspond to $20 \%$ of the most relevant articles. Thus, 1376 citations correspond to 79 articles aligned with the theme, not repeated and with scientific recognition.

The remaining articles, which are not within the most relevant $80 \%$ of citations, have been redirected to another article database. On that database, articles were reprinted per year, according to Table 2. The goal is to ensure that relevant articles are 
considered, even with a small number of citations. Thus, 32 articles were recovered, leaving 137 articles in total.

Table 2. Articles citation cut-off per year.

\begin{tabular}{lc}
\hline Year & Cut-off citation criteria \\
\hline $2014-2015$ & 10 \\
\hline 2016 & 6 \\
\hline 2017 & 2 \\
\hline 2018 & 0 \\
\hline
\end{tabular}

With the most relevant articles selected, the abstract was read to verify the relevance of the research before the proposed theme. After the reading, 100 articles were eliminated, remaining 37 articles that will be part of the bibliographic database.

\subsection{Bibliometric analysis of the portfolio}

With the portfolio research articles defined, the second stage of the ProKnow-C process corresponds to bibliometric analysis, where the main objective is to quantify the articles according to the research aspects.

Therefore, the aspects to be analyzed are: (i) impact factor; (ii) scientific recognition of the articles; (iii) relevance of periodicals; (iv) more prominent authors; (v) most commonly keywords; (vi) analysis of the evolution of the theme.

The impact factor is determined through the Journal Citation Report (JCR). The value of JCR is important as it provides information on the weight that each journal has on the article portfolio. We can see in Figure 1 that the Technovation and Research Policy journals were the ones that presented the highest JCR. The number of citations for each article was found. The objective is to quantify the recognition of each article in the academic environment. The result of this selection can be seen in Figure 2, where it shows that reference [11] is the most cited. Another important analysis is the relevance of periodicals. In this stage, the objective is to identify which journals have obtained the most number of articles, within the bibliographic portfolio. It is observed in Figure 3 that the CIRP Annals-Manufacturing Technology journal presents the most number of articles published. The authors with the most number of publications in the portfolio are presented in Figure 4. We can highlight the author Hoda Elmaraghy with the most number of publications, with a total of 5 publications.

To highlight the relevance of the bibliographic portfolio, the keywords most used by the authors are identified. This data shows how much a keyword is important within the search theme. Figure 5 shows that among the 80 keywords found in the bibliographic portfolio, the most outstanding was Product Platform described 7 times, followed by Modularity with 5, and Mass Customization with 4 occurrences.

The last bibliometric analysis was the evolution of the topic within the period of time covered by the article portfolio. The research was restricted to the period from 2014 to 2018 and Figure 6 shows the results. 


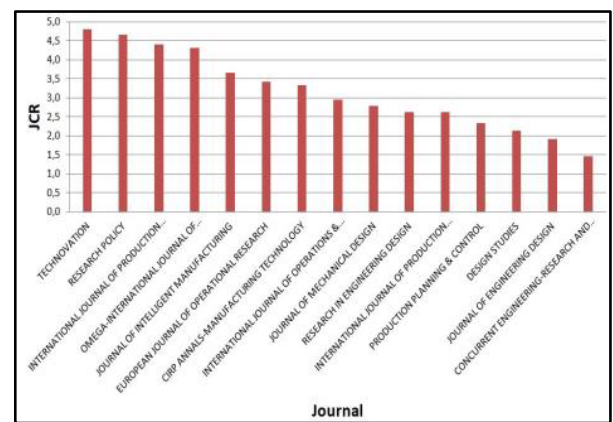

Figure 1. Journal citation report.

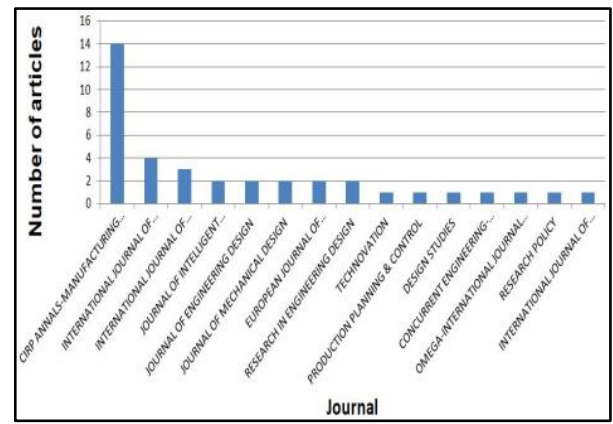

Figure 3. Journal relevance.

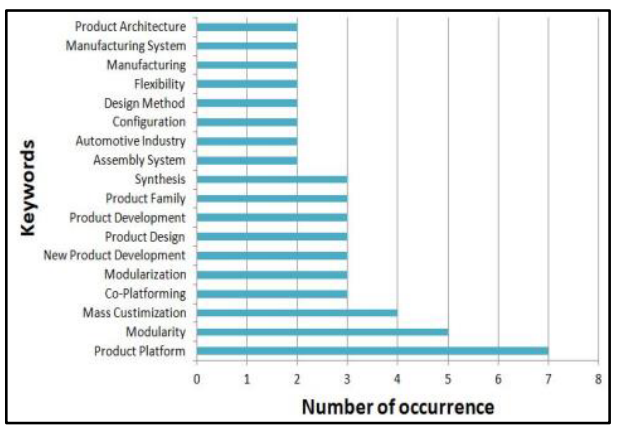

Figure 5. Number of occurrence.

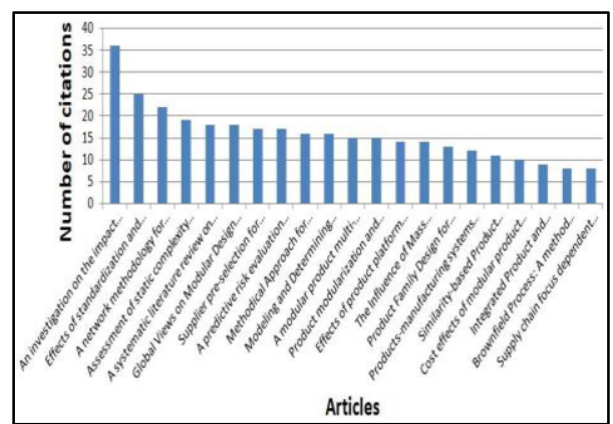

Figure 2. Number of citations.

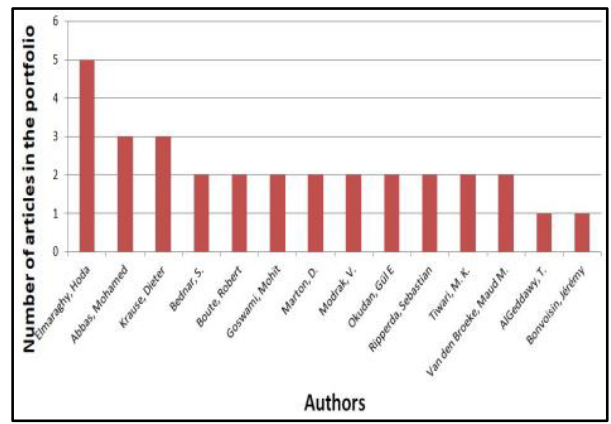

Figure 4. Number of citations.

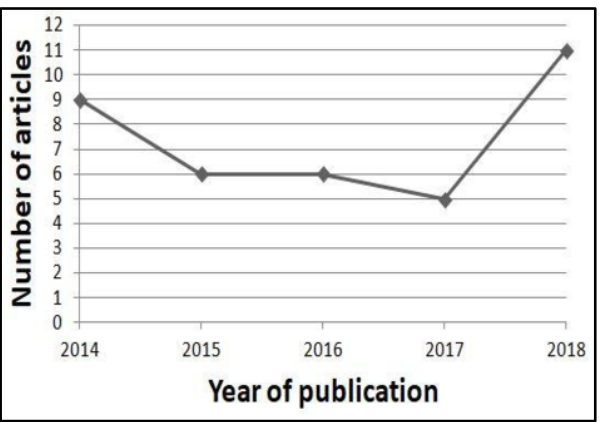

Figure 6. Year of publication.

\subsection{Systemic Analysis}

The main objective of the systemic analysis is to find trends and research opportunities, within the area of interest of the researcher. With this, the first step is to read all of the articles resulting from bibliometric analysis. The main reference for downloading the articles was Google Scholar [9]. Thus, 2 articles were not found, remaining 35 articles for reading. During the reading, 2 articles were not aligned with the research topic, leaving 33 articles that were considered in the systemic analysis. The systemic analysis aims to define the motivation that led to the research, the forms used to solve it and future research opportunities related to the topic. The systemic analysis process can be 
characterized as follows: (1) Research problems identified; (2) Objectives and proposed resources; (3) Identification of existing gaps.

With the definitions of the search information to be found, a tabulation of the information extracted from the article portfolio will be done, which will be presented next.

\subsubsection{Research problems identified}

Some of the identified research problems are presented in this section.

Poor configuration of the product family and its variants: Some authors treat the risk of an unsuccessful development of a product platform in terms of cost [2] and maintainability [12]. These are two important factors to consider as they will influence platform performance. According to [13], the functionality of the product is extremely important when it comes to business objectives that the company intends to achieve with the product platform. In this way, the correct definition of each product, and its functions is vital to the success of the industry.

An important issue raised by [14] and [15] is the allocation and arrangement of the different assembly modules. The optimization of the modules arrangement provides cost reduction and saves assembly time. Similar products should avoid using different modules with the same function [16].

Inefficiency of product platform development process: Thus, [11] and [17] deal with the relationship between product modularity and the supply chain, which should be considered during the development phases. The organization and interface between different areas during the development process is a great challenge for many companies [18], taking into account the complexity of developing a platform for a family of products.

During the product development process (PDP) many decision-making becomes necessary. One of the most important is when it comes to the definition of a platform. Several criteria are used, but one of the most important is cost $[19,20]$, especially when dealing with multiple alternatives for platform choice. In the same context, [21] refers to the market requirements where the platform will be offered. These should be raised in order to contribute to the better definition of the platform. The PDP model can be influenced by the platform configuration itself and the product family derived from it [22].

Manufacturing and assembly issues for platform-based products: A platform should be developed with the aim of making its manufacturing process as optimized as possible [23]. A family of products that will be assembled from a platform tends to be configured to extract the maximum possible use of the production line. In this way, it is also necessary that the production line must be able to adapt to different product line assemblies [24]. Thus, the assembly modules of the different product variants should be designed with their functionality in mind, as well as their manufacturing and assembly on the line [25].

The complexity of platform variant products is one of the main factors of manufacturing impact [26]. According to [27] and [28], the high complexity of product variants in the production line has a negative impact on manufacturing performance.

The production time of a platform-based product family is the primary means of measuring production performance [29]. Several factors affect this indicator, among the main we have tool change time [30], which is strongly impacted by the complexity between different product configurations. We have other important metrics that 
measure manufacturing performance. As for example the quality of the assembly, which also suffers strongly influence of the complexity of the products [31].

\subsubsection{Objectives and proposed resources}

In this section is presented the objectives and proposed resources.

Regarding the poor configuration of the product family and its variants, [32] has created a method for modeling new product family structures, becoming them easy to visualize and interchangeable. In the same line of this research, [12] develop a methodology for prediction of failures in modular products, focusing on maintainability of the platform.

Authors from [15] proposed a methodology to configure products by similarity, optimizing the use of the platform. In the same research line, [16] develops a model to minimize the allocation of the assembly modules in the various product variants. Models based on product platform configuration, that supporting the decision of standardization or customization of products in multiple markets are treated by [33] and [16].

The configuration problems present different focuses such as cost optimization and production performance. The research presented in [2], develops a method which aims to create a portfolio of platforms with minimal cost. Cost is related to the difference between platform and product performance. The best configuration of the assembly modules was treated by [34], where a framework was created in order to find the most appropriate product configuration for the assembly line. Integration between different areas is treated by [11], the authors develop a methodology that aims to integrate the decisions made by the supply chain and product design team, at early stages of development. The results indicate that the rearrangement of the existing supply chain, based on product characteristics, can significantly improve the performance of the entire system.

There are several articles approach, which relate to problems of the manufacturing process and assembly of product platforms. This is treated objectively in [26], where a metric is created to evaluate the impact of product complexity on production time and total cost. The study shows that the greater the complexity of the product and the production process, the worse results are found in the time and cost of production, especially under higher production volumes. The modularization of production is also reported in [35] and [30], which respectively develop a methodology and model, where the concept of co-production platform is described. This concept describes that the production line can also be reconfigured, in terms of the machine platform. Thus, the tooling changes are faster or can be considered minimum changes, for different product configurations. A model based on fuzzy logic is presented by [36], which aims to optimize the assembly of the modules, considering assembly procedures, equipment, and parts to be assembled. The effects of product modularity are studied by [31], in terms of the complexity perceived by assembly line operators and the quality of production. A method developed by the authors has shown the importance of having a good assembly information system for operators, especially when it comes to a high variety of products.

\subsubsection{Identification of existing gaps}

The main gaps are listed below. 
Optimization of platform-based product family configuration: According to [12], the inefficient configuration of the product family occurs when the PDP does not connect the functionality of the modules to market expectations. The family of products is often developed without paying attention to what the market really needs, compared to what the product offers. This may cause some product acceptance issues. The work presented in the article [33] suggests a more in-depth study of what different markets expect from products coming from the same platform, considering functionality. On the other hand, the decision to standardize or customize products for different markets also raises questions about the efficient configuration of product families [16]. This approach is proposed by [3], where gaps regarding the impacts of standardization or customization can still be explored. As for example, impact on product quality, customer safety, among others.

Improvement in the process of developing new product platforms: The research presented by [18], suggest extending this gap to global companies, with offices in several countries, where communication is more inefficient due to distance. Communication problems can occur at any point in the platform development process that requires some interface between different areas. As presented by [3], this point may even be in the supply chain. The impacts on vendors that can come from platform development can be further explored. According to [11], a more efficient integration between engineering and suppliers, from the early stages of development, can be better investigated, taking into account the impacts of platform design changes in the supply chain.

Within the PDP there is another critical path of information flow, which is the engineering and production team. When it comes to platform development, this interface must be constantly improved to maximize the benefits of using mass customization platforms [37]. According to [22], enhancements in the performance of product and production engineering during the platform development can be better investigated considering aspects of production capacity, resource constraints, and demand forecasting.

Impact of the product platform on the production line: The relationship between the product family and its production line is treated as an issue not yet resolved by the authors.

In this case, several studies tend to solve the problem of the impact of product variants on the production line. For this, the concept of co-platform is cited by [30] and [35]. This concept deals with the tool platform that is used to assemble different product variants. [30] developed a method that, through a design matrix, maps the product platform and the manufacturing platform, connecting the two platforms to choose the best way to manufacture their respective product families.

In the same line of research, [31], study the impact of the complexity of product variants on manufacturing quality. The optimization of production for different assemblies of the product family is a gap that still requires many studies [36]. The impact on the assembly line, product modules, mass customization, among other aspects related to platforms, still generate many research opportunities [24]. With this, there is still no complete understanding of the impact of variants or product configurations on the production line. 


\section{Conclusions}

This work aimed to look for trends and opportunities for research in the area of product platform applied to mass customization. In order to create a based article portfolio, the research tool ProKnow-C tool was used.

From the literature review, an article database was built to form an understanding of the topic. A bibliometric analysis was performed, which seeks to quantify the articles in the aspects of: i) impact factor; ii) scientific recognition of articles; iii) relevance of periodicals; iv) authors of greater prominence; v) most commonly used keywords; and vi) analysis of the evolution of the theme. Finally, the systemic analysis intended to extract information from the portfolio such as: (1) Research problems identified; (2) Proposed objectives and resources; (3) Identification of existing gaps. Thus, a bibliographic portfolio containing a total of 33 articles were read and at the end was possible to list some research opportunities. Among them, we can highlight: (i) Optimization of the configuration of the product family based on platform; (ii) Improvement in the process of developing new product platforms; (iii) Impact of the product platform on the production line. Thereby, the present research was effective in finding trends and research opportunities in the proposed theme.

As a suggestion for future work, we can highlight a review in the reading of the titles of articles in the initial stage of the bibliographic review, which can be considered very carefully, since many articles were eliminated. Another suggestion is to increase the amount of search database in order to increase the capture of relevant articles.

\section{References}

[1] G. Schuh, C. Doelle, J. Koch, and P. Grutza, Identification of the cost-benefit-optimal product configuration, Procedia CIRP, 2018, vol. 70, pp. 386-391.

[2] M. Van den Broeke, R. Boute, B. Cardoen, and B. Samii, An efficient solution method to design the cost-minimizing platform portfolio, European Journal of Operational Research, 2017, vol. 259, pp. 236-250.

[3] C. Karlsson and M. Sköld, Specialization and commonalization in multi-branded manufacturing corporations: Learnings from automotive industries, Int. J. Oper. Prod. Manag., 2018, vol. 38, no. 1, pp. 67-89.

[4] L. Ensslin, S. Ensslin, R. Laceda, E. Tasca, ProKnow-C, knowledge development processconstructivist, Processo técnico com patente de registro pendente junto ao INPI. Brasil, 2010, vol. 10, p. 2015.

[5] R. T. d. O. Lacerda, L. Ensslin, and S. R. Ensslin, A bibliometric analysis of strategy and performance measurement, Gestão \& Produção, 2012, vol. 19, pp. 59-78.

[6] E.L. Silva and E. M. Menezes, Metodologia da pesquisa e elaboração de dissertação, Florianópolis, 2005 .

[7] A. C. Gil, Como elaborar projetos de pesquisa, São Paulo, 2002, vol. 5, p. 61.

[8] J.S. Dienstmann, R.T.O Lacerda, L. Ensslin, S.R. Ensslin, Gestão da Inovação e Avaliação de Desempenho: processo estruturado de revisão da literatura, Revista Científica Eletrônica de Engenharia de Produção, Florianópolis, 2014, vol. 14, pp. 2-30.

[9] Google Scholar. Accessed: Jul, 01 2018. [Online]. Available: www.scholar.google.com.br

[10] A. Bommier and S. Zuber, The Pareto principle of optimal inequality, International Economic Review, 2012, vol. 53, pp. 593-608.

[11] M. C. Chiu and G. Okudan, An investigation on the impact of product modularity level on supply chain performance metrics: An industrial case study, Journal of Intelligent Manufacturing, 2014, vol. 25, no. 1, pp. 129-145.

[12] M. Goswami and M. K. Tiwari, A predictive risk evaluation framework for modular product concept selection in new product design environment, J. Eng. Des., 2014, vol. 25, no. 1-3, pp. 150-171. 
[13] M. Goswami, Y. Daultani, and M. K. Tiwari, An integrated framework for product line design for modular products: product attribute and functionality-driven perspective, International Journal of Production Research, vol. 55, 2017, pp. 3862-3885.

[14] K. Sinha and E. S. Suh, Pareto-optimization of complex system architecture for structural complexity and modularity, Research in Engineering Design, 2018, vol. 29, pp. 123-141, 2018.

[15] G. Schuh, S. Rudolf, and M. Riesener, Similarity-based product configuration, Procedia CIRP, 2014, vol. 17 , pp. $290-295$.

[16] Z. Wang, M. Zhang, H. Sun, and G. Zhu, Effects of standardization and innovation on mass customization: An empirical investigation, 2016, Technovation, vol. 48-49, pp. 79-86.

[17] Y. Cao, X. Luo, C. K. Kwong, and J. Tang, Supplier pre-selection for platform-based products: A multi-objective approach, 2014, International Journal of Production Research, 2014, vol. 52, pp. 1-19.

[18] Y. Liu, X. Liang, and Y. Shi, Brokerage and balance: Creating an effective organizational interface for product modularization in multinational R\&D, Research Policy, 2018, vol. 47, pp. 1133-1146.

[19] S. Ripperda and D. Krause, Cost Effects of Modular Product Family Structures: Methods and Quantification of Impacts to Support Decision Making, Journal of Mechanical Design, 2017, vol. 139, pp. 021103-1-021103-12.

[20] M. M. Van den Broeke, R. N. Boute, and J. A. Van Mieghem, Platform flexibility strategies: R\&D investment versus production customization tradeoff, European Journal of Operational Research, 2018, vol. 270, pp. $475-486$.

[21] Y. Yin, I. Kaku, and C. Liu, Product architecture, product development process, system integrator and product global performance, Production Planning \& Control, 2014, vol. 25, pp. 203-219.

[22] F. A. S. Piran, D. P. Lacerda, L. F. R. Camargo, C. F. Viero, A. Dresch, and P. A. Cauchick-Miguel, Product modularization and effects on efficiency: An analysis of a bus manufacturer using data envelopment analysis (DEA), International Journal of Production Economics, 2016, vol. 182, pp. 1-13.

[23] M. Hanafy and H. Elmaraghy, A modular product multi-platform configuration model, International Journal of Computer Integrated Manufacturing, 2015, vol. 28, pp. 999-1014.

[24] U. Wagner, T. AlGeddawy, H. ElMaraghy, and E. Müller, Product family design for changeable learning factories, Procedia CIRP, 2014, vol. 17, pp. 195-200.

[25] M. Abbas and H. ElMaraghy, Co-platforming of products and assembly systems, Omega, 2018, vol. 78, pp. 5-20.

[26] K. Park and G. E. Okudan, Int . J . Production Economics Assessment of static complexity in design and manufacturing of a product family and its impact on manufacturing performance, International Journal of Production Economics, 2015, vol. 169, pp. 215-232.

[27] M. Landherr and E. Westkämper, Integrated product and assembly configuration using systematic modularization and flexible integration, Procedia CIRP, 2014, vol. 17, pp. 260-265.

[28] V. Modrak, D. Marton, and S. Bednar, Modeling and determining product variety for mass-customized manufacturing, Procedia CIRP, 2014, vol. 23, no. C, pp. 258-263.

[29] S. Nagahara and Y. Nonaka, Product-specific Process Time Estimation from Incomplete Point of Production Data for Mass Customization, Procedia CIRP, 2018, vol. 67, pp. 558-562.

[30] H. ElMaraghy and M. Abbas, Products-manufacturing systems Co-platforming, CIRP Annals, 2015, vol. 64 , pp. $407-410$.

[31] P. E. C. Johansson, S. Mattsson, L. Moestam, and Å. Fast-Berglund, Multi-variant Truck Production Product Variety and its Impact on Production Quality in Manual Assembly, Procedia CIRP, 2016, vol. 54, pp. 245-250.

[32] B. Fan, G. Qi, X. Hu, and T. Yu, A network methodology for structure-oriented modular product platform planning, Journal of Intelligent Manufacturing, 2015, vol. 26, pp. 553-570.

[33] S. Jonnalagedda and H. Saranga, Commonality decisions when designing for multiple markets, European Journal of Operational Research, 2017, vol. 258, pp. 902-911.

[34] V. Modrak, D. Marton, and S. Bednar, The influence of mass customization strategy on configuration complexity of assembly systems, Procedia CIRP, 2015, vol. 33, pp. 538-543.

[35] M. Abbas and H. ElMaraghy, Synthesis and optimization of manufacturing systems configuration using co-platforming, CIRP Journal of Manufacturing Science and Technology, 2018, vol. 20, pp. 51-65.

[36] W. Ren, Y. Guan, and Y. Hu, ScienceDirect Research on assembly module partition for flexible production in mass customization, Procedia CIRP, 2018, vol. 72, pp. 744-749.

[37] P. E. Harland and Z. Uddin, Effects of product platform development: fostering lean product development and production, International Journal of Product Development, 2014, vol. 19, p. 259. 